\title{
Does the level of asepsis impact the success of surgically implanting tags in Atlantic
} salmon?

Jepsen, Niels; Boutrup, Torsten S.; Midwood, Jonathan D.; Koed, Anders

Published in:

Fisheries Research

Link to article, DOI:

10.1016/j.fishres.2013.07.017

Publication date:

2013

Link back to DTU Orbit

Citation (APA):

Jepsen, N., Boutrup, T. S., Midwood, J. D., \& Koed, A. (2013). Does the level of asepsis impact the success of surgically implanting tags in Atlantic salmon? Fisheries Research, 147, 344-348.

https://doi.org/10.1016/j.fishres.2013.07.017

\section{General rights}

Copyright and moral rights for the publications made accessible in the public portal are retained by the authors and/or other copyright owners and it is a condition of accessing publications that users recognise and abide by the legal requirements associated with these rights.

- Users may download and print one copy of any publication from the public portal for the purpose of private study or research.

- You may not further distribute the material or use it for any profit-making activity or commercial gain

- You may freely distribute the URL identifying the publication in the public portal 
Fisheries Research 147 (2013) 344- 348 http://dx.doi.org/10.1016/j.fishres.2013.07.017 C Elsevier

DTU Aqua

National Institute of Aquatic Resources

DTU Veterinary

National Veterinary Institute

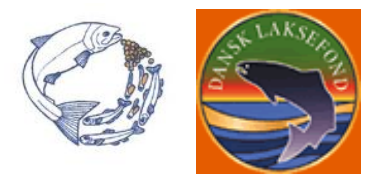

\title{
Does the level of asepsis impact the success of surgically implanting tags in Atlantic salmon?
}

\author{
Niels Jepsen ${ }^{a},{ }^{*}$, Torsten S. Boutrup ${ }^{b}$, Jonathan D. Midwood ${ }^{c}$, Anders Koed $^{a}$ \\ ${ }^{a}$ DTU Aqua, Section for Freshwater Fisheries and Ecology, Vejlsøvej 39, 8600 Silkeborg, Denmark \\ ${ }^{b}$ DTU Vet, Section for Virology, Division of Fish Diseases, Hangøvej 2, 8200 Aarhus, Denmark \\ ${ }^{c}$ Carleton University, Department of Biology and Institute of Environmental Science, 1125 Colonel By Dr., \\ Ottawa, ON, Canada
}

\begin{abstract}
It is generally recommended that a high level of asepsis be maintained during surgical implantation ofelectronic tags into fish. However, documentation of a positive effect of asepsis in fish surgery is lacking. Tocompare the effects of surgical implantation performed under different sanitary conditions, 100 hatcherysalmon smolts (Salmo salar) were surgically implanted with tags with and without trailing antenna andwere kept in a hatchery facility. After 34 days, the surviving smolts were euthanized and survival, growthand healing were compared between fish tagged under aseptic conditions and fish tagged without regardto aseptic technique. The results demonstrated that there was no detectable difference in survival, growthand healing between the treatments. Thus, this study could not provide evidence supporting the generalrecommendation of achieving a high level of asepsis during fish surgery.
\end{abstract}

Keywords: Tagging effects, Asepsis, Wound healing, Suture Infections;

*Corresponding author: nj@aqua.dtu.dk (N. Jepsen).

Article first published online: Accepted 21 July 2013

Please note that this is an author-produced PostPrint of the final peer-review corrected article accepted

for publication. The definitive publisher-authenticated version can be accesses here:

http://dx.doi.org/10.1016/j.fishres.2013.07.017 @ Elsevier 
Does the level of asepsis impact the success of surgically implanting tags in Atlantic salmon?

NIELS JEPSEN $^{1 *}$, TORSTEN S. BOUTRUP ${ }^{2}$, JONATHAN D. MIDWOOD ${ }^{3} \&$ ANDERS KOED $^{1}$

11 Running headline: Asepsis in fish surgery?

1) DTU Aqua, Section for Freshwater Fisheries and Ecology, Vejlsøvej 39, 8600 Silkeborg

2) DTU Vet, Section for Virology, Division of Fish Diseases, Hangøvej 2, 8200 Aarhus

3) Carleton University, Department of Biology and Institute of Environmental Science, 1125 Colonel By Dr. Ottawa, ON, Canada

- Corresponding author. Tel.: +4535883131, E-mail address: nj@ aqua.dtu.dk 


\section{Abstract}

39 It is generally recommended that a high level of asepsis be maintained during surgical implantation

40 of electronic tags into fish. However, documentation of a positive effect of asepsis in fish surgery is

41 lacking. To compare the effects of surgical implantation performed under different sanitary

42 conditions, 100 hatchery salmon smolts (Salmo salar) were surgically implanted with tags with and

43 without trailing antenna and were kept in a hatchery facility. After 34 days, the surviving smolts

44 were euthanized and survival, growth and healing were compared between fish tagged under aseptic

45 conditions and fish tagged without regard to aseptic technique. The results demonstrated that there

46 was no detectable difference in survival, growth and healing between the treatments. Thus, this

47 study could not provide evidence supporting the general recommendation of achieving a high level

48 of asepsis during fish surgery.

49

55 Key words: tagging effects, asepsis, wound healing, suture, infections 
59 Many important management decisions are based upon results from telemetry studies. Numerous

60 studies have demonstrated that electronic tags can be surgically implanted and carried by some fish

61 for long periods without significant effect on mortality (Reviewed in: Cooke et al., 2011); however,

62 results may still be compromised by sub-lethal effects brought about by the treatment. Reported

63 sub-lethal effects of surgical implants include decreased swimming capacity (e.g. McCleave and

64 Stred, 1975; Arnold and Holford, 1978), reduced growth (e.g. Greenstreet and Morgan, 1989;

65 Jepsen et al., 2008) and tag expulsion (e.g. Chisholm and Hubert, 1985; Marty and Summerfelt,

66 1986; Jepsen et al., 2008). Partitioning the extent to which these sub-lethal effects are caused by the

67 surgery rather than the presence of the tag itself can be challenging, yet is essential for

68 interpretation of telemetry results as well as for improving tagging protocols.

69

70 In addition to concerns over the validity of the results, the ethics of the methodology attract

71 attention because researchers are obligated to refine techniques to ensure better animal welfare. To

72 limit potential sub-lethal effects from surgery, it is important for both veterinarians and biologists to

73 reduce infection in relation to surgical implants in fish. For example, although there is no published

74 evidence that pathogen transmission has occurred during transmitter implant surgeries, there is

75 evidence that transmission of Renibacterium salmoninarum, (the cause of BKD) increased among

76 juvenile Chinook salmon (Oncorhynchus tshawytscha) by coded-wire tagging procedures (Elliott

77 and Pascho 2001).

78

79 It is clearly of the utmost importance to assure sterile or aseptic conditions when performing

80 surgery in the body-cavity of mammals or birds, but how important is this for fish? In theory, it

81 would be beneficial to perform fish surgery under totally aseptic conditions to minimize the risk of 
infection and disease. However, procedures used for mammals (drying, rinsing the skin with chemicals) are generally harmful for fish. Any complication that prolongs the time of surgery may also have negative effects on the fish. It is clear there are pros and cons, but little documentation on this issue; Chomyshyn et al. (2011) addressed this and acknowledged that the few studies that have investigated have failed to document a positive effect of aseptic techniques, prophylactic or postoperative treatments, but still recommend aiming for a high level of asepsis. Furthermore, Mulcahy (2003) states:

"The surgical implantation of a non-sterile transmitter into any animal is an inhumane act, which should not be performed. Fish, like mammals, are susceptible to infections from contaminated implants."

This highlights the assumption that fish surgery is comparable to mammalian surgery and therefore aseptic conditions are equally critical. Mulcahy (2011) further argues that instead of using antibiotics, more care should be taken in attaining asepsis, even under field conditions. Harms and Lewbart (2011) are in agreement suggesting that while "sterile surgery" is likely impossible in the field, most aseptic techniques can be adopted without making surgeries unnecessarily long. It should be noted however, that despite the wise adoption of asepsis in terms of the precautionary principle, neither Mulcahy (2003) nor Harms and Lewbart (2011) directly evaluate whether aseptic conditions are necessary. Therefore despite recommendations from veterinarians, there is no clear evidence of a need for asepsis.

Such recommendations are indeed an integral part of most standard operating procedures for surgical fish tagging (e.g. Brown et al., 2010; Liedtke et al., 2012) as well as in the guidelines from the Canadian Council on Animal Care (2005). However, many experienced fish surgeons and researchers have attained a clear perception that for standard fish surgery under normal conditions 
106 (good water quality, moderate water temperatures), attempts to decrease the risk of infection by 107 instituting extensive aseptic procedures have no effect (e.g. Wagner and Cooke, 2005). Wagner et 108 al. (1999) tested the effect of prophylactic preparation with a povidone-iodine antiseptic prior to 109 conducting surgery on rainbow trout (Oncorhynchus mykiss), but found no clear effect. In a field 110 study where $100 \%$ of tagged fish were recaptured after one year in a reservoir, no negative effects 111 (on growth, survival, performance) of surgical implants with trailing antenna were found, even 112 though surgery was performed under field conditions with no prophylactic or postoperative 113 treatments (Jepsen et al., 1999; 2000). Similarly, Koed and Thorstad (2001) found no long-term 114 effect of radio tagging on the swimming performance of fish more than one year after non aseptic 115 tagging. Chomyshyn et al. (2011) tested if the intrusion of lake water into the coelom had negative 116 effects on survival and healing of bluegill (Lepomis macrochirus) and results showed no positive 117 effect of avoiding water entry or using sterile/aseptic equipment. Thus, there are currently no 118 published papers documenting a positive effect of reducing the risk of infection. One can therefore 119 argue that until such documentation appears, it can be assumed that infection is not a common 120 problem in fish surgery and as such efforts should be focused on improving capture, handling and 121 holding conditions rather than on keeping clean conditions and using sterilized tools during tagging.

123 In a recent review paper, Cooke et al. (2011) highlighted the need for focused research on the topic 124 of asepsis in fish surgery. Therefore, our objectives are to experimentally test whether there are 125 significant differences in growth, survival and healing between fish that have tags surgically 126 implanted under aseptic (clean) and non-aseptic (dirty) conditions. In addition, we investigate 127 whether the presence of an external trailing antenna further impacts post-operative recovery. 
131 fish collected in River Skjern, Denmark. We randomly assigned each fish to one of two treatment groups representing two different degrees of asepsis. The "clean" treatment incorporated all aseptic

133 practices that are widely included in many guidelines for fish surgery (e.g., CCAC 2005). In

134 contrast, since ensuring aseptic conditions is often not possible or practical in the field, the non-

135 aseptic treatment represented an extreme example of in situ surgery where no attempt was made to

136 limit exposure to pathogens. Specifically for the aseptic treatment, all dummy tags were sterilized in

137 an autoclave and packed separately. All surgical tools were also sterilized in an autoclave prior to

138 the surgical procedure. In between surgeries on separate fish, needle-holders, handles for scalpel

139 blades and hollow needles for antenna placement were rinsed in $97 \%$ ethanol and dried. A new

140 sterile scalpel blade and new sterile suture with needle (Vicryl 5-0 FS-2; Ethicon, Piscataway, NJ,

141 U.S.A.) were used for each new fish. The surgeon wore a new set of standard (non-sterile) surgical

142 gloves for each fish. The surgical table and support pillow were cleaned between each fish by

143 rinsing with ethanol, drying and changing the sheet of laboratory paper. In contrast, for the non-

144 aseptic treatment, dummy tags were not sterilized, nor rinsed in ethanol. All surgical tools including

145 sutures and scalpel blades were previously used at least once (for the clean surgery) and not cleaned

146 between surgeries. No gloves or masks were used and the surgical table was not cleaned between

147 surgeries.

149 In addition to separating the fish into aseptic and non-aseptic treatments, we tagged half of each 150 treatment group (25 aseptic and 25 non-aseptic) with dummy tags $(6 \times 20 \mathrm{~mm}, 0.5 \mathrm{~g}$ weight in air)

151 that had no antenna (NA), and half with tags $(6 \times 20 \mathrm{~mm}, 0.7 \mathrm{~g}$ weight in air) that had a trailing 152 antenna (A). Antennas were trimmed down to not exceed the caudal fin by more than $5 \mathrm{~cm}$. This 153 second layer of treatment was incorporated to evaluate the potential additional complications from 
an external antenna. The experimental fish ranged in size from $14.5-20.5 \mathrm{~cm}$ with weights from 28 - 88g. Tag/body mass ratios ranged from $0.7-2.4 \%$ (mean A: $1.07 \%$; NA: $1.71 \%$ ).

An experienced fish surgeon performed surgical implants in accordance to the guidelines described in permission (2012-DY-2934-00007) from the Danish Experimental Animal Committee. The surgical procedure followed that described in Jepsen et al. (1998) and the incisions were closed with a single absorbable suture. After treatment and recovery (10-20 min) all fish were released back into their original tank. The dummy tags consisted of simulated tags used in studies of smolt migration (i.e. Jepsen et al., 2000; Hockersmith et al., 2003) and were obtained from Advanced Telemetry Systems (Isanti, MN, USA). The surgeries were performed on 28 July 2011 and the study was terminated on 31 August 2011. After surgery, a total of 16 (4 of each treatment group) tagged smolts were placed in a separate tank for monitoring short-term effects. These were euthanized and examined five days after tagging.

All fish were measured and weighed within a few hours post euthanization. Each fish was necropsied and a photo was taken to document healing and tissue reaction. The remaining 84 fish were housed for 34 days before ultimately being euthanized. These fish were measured and weighed within a few hours post euthanization and each fish was necropsied to determine the level of inflammation, adhesion, tag encapsulation within the body cavity as well as the position of the tag (e.g., free floating, in a pocket, in the process of being expelled). Healing of the incisions was evaluated using a rating scale that ranged from 1-4 (adapted from Wagner et al. 2000), one being a perfectly healed, healthy incision, and four being an open wound with severe inflammation.

\section{Statistics}


A multinomial regression with healing (1-4) as the dependent factor and degree of asepsis (aseptic/non-aseptic), maturity (yes/no) and antenna type (A/NA) as the independent factors and length as a covariate was performed.

A General Linear Model (GLM) with specific length growth $\left(\mathrm{G}_{\mathrm{L}}=\left(\ln \mathrm{L}_{2}-\ln \mathrm{L}_{1}\right) * t^{-1}\right)$ as the dependent factor and degree of asepsis (aseptic/non-aseptic), antennas (A/NA) and maturity (mature/nonmature) as fixed factors and length as covariates was performed. All the interaction terms were included in the analysis using a backward elimination approach using IBM SPSS Advanced Statistics 20.0.

\section{Results}

The whole procedure for each implant in the aseptic procedure took approximately eight minutes, whereas implanting the dummies in the non-aseptic procedure took approximately four minutes. However, the actual time that each fish was handled did not differ between treatments. Instead, the longer time was due to the extra steps required between the aseptic surgeries, i.e. changing gloves, scalpel blades and sutures as well as cleaning and drying equipment.

Most experimental fish survived and performed well during the study; however, a problem with the water quality in the facility caused some mortality of both the experimental fish and untagged fish in adjacent tanks. This occurred between 24-27 days after the surgery and a total of 10 experimental fish, all mature males, died. Thus, the analyses of growth, healing and survival were based on 100 minus 16 (pre-sampled) minus $10(\mathrm{dead})=74$ individuals. Most fish were observed feeding 
not eat much and experienced negative growth. Length changes ranged from $0-2.9 \mathrm{~cm}$ and weight from -7 to 30 grams. The specific growth for each treatment group is shown in Table 1.

For the 16 fish examined five days after tagging, there were no clear differences in tissue reaction between the two treatments (Table 2). A high degree (13 of 16 fish) of tissue adhesion to the body wall at or close to the incision site was observed. The adhesions were fragile fibrinous adhesions and were seen from the dummy tags (with or without the antenna), and also from internal organs

210 (i.e., spleen, intestine, testes) separately without involvement of the dummy or antenna. For some 211 fish (3 of 16), hemorrhages were apparent as part of the acute inflammatory response to the 212 incision.

214 Post-mortem examinations of smolt 34 days after tagging revealed that about half (53\%) of them 215 were sexually mature males (mature male parr). A high degree (64 of 74 fish) of tissue adhesion 216 was also observed at this time (Table 2); the extent of the adhesions was comparable to those seen 217 five days after tagging but at this time the exudates had reorganized into a fibrous tissue.

218 Hemorrhages were only seen in a small number (9 of 74) of fish (Table 2), indicating that some 219 acute inflammatory reactions were still active. In 24 fish, the dummy tag was free in the body 220 cavity; in the other 50 it was either encapsulated by a thick brim of fibrous tissue or resting in a 221 "pocket". The "pocket" consisted of a very thin, sometimes transparent, membrane arising within 222 the omentum of the intestines around the stomach. The nature of the pocket is unclear; it might be 223 an outpouch on the omentum trying to embrace the foreign body for immobilization, or an 224 inflammatory reaction with a very small amount of exudation, which when uncomplicated, could reorganize into a fine membrane. 
After 34 days, most incisions had healed well, with minimal differences in the average healing score between aseptic (1.84) and non-aseptic (1.74) treatments. However, of the 74 examined fish, $47(64 \%)$ still had some absorbable suture material present. Multinomial regression demonstrated that there were no statistically significant effects of either the degree of asepsis $(p=0.830)$, maturity $231(\mathrm{p}=0.617)$, antennas $(\mathrm{p}=0.614)$, or length $(\mathrm{p}=0.694)$ on the degree of healing. The general linear 232 model demonstrated that while there was a statistically significant effect of length $\left(\mathrm{GLM} ; \mathrm{F}_{1,69}=\right.$ $23318.95 ; \mathrm{p}<0.001)$ and maturity $\left(\mathrm{GLM} ; \mathrm{F}_{1,69}=7.787 ; \mathrm{p}=0.007\right)$ on specific length growth, there 234 were no effects of degree of asepsis $(p=0.631)$ or antennas $(p=0.353)$ and none of the interaction terms were statistically significant $(\mathrm{p}>0.05)$.

\section{Discussion}

This study demonstrated that no apparent benefit was achieved by ensuring a very high degree of asepsis during surgery, compared to a simple field-like procedure. This result is similar to what was reported by Chomyshyn et al. (2011). Obtaining a high degree of asepsis will significantly increase equipment costs and was found to double the total time between surgeries. Both time and cost are of great importance for studies that involve tagging a large number of individuals. The two groups of 243 fish here were tagged under extremely clean and extremely unclean conditions, respectively, and 244 still they performed equally well, highlighting the questionable value of asepsis in fish surgery. The 245 fact that no attempts were made to achieve asepsis does not necessarily mean that there was a 246 significant load of pathogens present during the non-aseptic surgery. However, we deliberately 247 chose hatchery Atlantic salmon in the period after their normal smolt migration, because they are 248 known to be sensitive to diseases (high mortality), when kept in the hatchery after their normal 249 migration period. Still, it is not possible or prudent solely on the basis of the present results to 
recommend abandoning the use of asepsis in field tagging of fish, but we hope to encourage a

251 discussion of whether it is necessary to require "the highest attainable level of asepsis" as a

252 standard.

Overall, the fish recovered quickly post-surgery and were observed to have resumed feeding within

24 hours. The mortality observed (regardless of treatment) was in the expected range for postsmolts held in freshwater (Jepsen et al., 2001) and was similar to mortality rates among untagged fish in adjacent tanks (data not shown). From the post-mortem examination of the fish, five and 34 days after tagging, no significant difference was found between fish tagged under aseptic or nonaseptic conditions.

261 Recently, Daniel et al. (2009) described tag expulsion by common carp (Cyprinus carpio) and 262 related this to "infection associated with the sutures/incision". Such observations are not uncommon 263 in the literature and could be seen as evidence that infections are indeed a major problem in fish 264 surgery. In fact, putting fish back into a potentially contaminated environment with a breach in the 265 integument could be more of a problem than the surgery itself. Nonetheless, we still lack 266 documentation that 1) these problems really are caused by "infected incisions" and not just tissue 267 reaction or necrosis in the presence of sutures and the tag and 2) that a high level of asepsis can 268 reduce the risk of such problems. Studies documenting problems associated with infections from 269 tagging as well as studies demonstrating that these issues can be solved by improving the protocol 270 (i.e., aseptic techniques) are greatly needed and should be possible to conduct if the problem really 271 is evident. 
Similar to observations by Bauer et al. (2005), Mesa et al. (2011), Sandstrom et al. (2013) and Wagner et al. (2000), it seems clear that suturing was the main cause for complications in our study scar tissue, where the longitudinal line (the original incision) was less pronounced than the line from the suture material. The same was observed in wild trout, recaptured several months after tagging (Jepsen et al., 2008). Thus, optimization of the suturing process and material may be more important than level of asepsis for wound healing and the prevention of infection. Relevant issues here include how fast the absorbable material dissolves, the diameter and type of material, and how to suture to give the most support to the tissue for optimal healing.

In this study, there was an unexpectedly high degree of tissue adhesion between the organs and the body wall at the position of the incision (Table 2). The reason for this is unknown, and there were no differences among treatment groups. In a similar post tagging evaluation (Jepsen et al., 2008) of wild trout with similar tag/body mass ratios $(0.6-3.9 \%)$, very little adhesion was observed. This evaluation was 5-6 months post-surgery, so it is possible that tissue adhesion represents an 288 intermediate state in the healing process.

In this study, the gross lesion pattern did not indicate the presence of a bacterial infection, specifically where adhesion of the telemetric dummy tag to the abdominal wall could be interpreted as the beginning of expulsion of the dummy. However, no bacterial cultures were collected from the 293 fish so we cannot exclude the possibility of a bacterial infection. Some post tagging infections in 294 fish have been reported but these have been described as being of a secondary nature rather than 295 introduced due to a breach in asepsis during/at the time of the surgical procedure (see Mellas and 296 Haynes, 1985). Indeed, Daniel et al. (2009) state: 


$$
\text { high". }
$$

In terms of the presence or absence of an antenna on the dummy tags, consistent with Jepsen et al. (2008), we observed only marginally reduced growth of trout tagged with trailing antenna compared to fish without antenna; however, this was not a significant factor in the multinomial regression. Similarly, antenna presence/absence was not found to play a significant role in healing.

A possible caveat for this study, is that we chose to use fish that were in a stressed state; they were possibly experiencing "frustrated smolt syndrome" because they were held up or confined after they had adapted physiologically to enter seawater (e.g. Jepsen et al., 1998; Wargo Rub et al., 2011). Transferring the fish to salt water tanks could have mitigated this, but since we wished to be able to detect potential differences in healing and infections, it was decided that fish should be kept in the more stressful and potentially more pathogenic freshwater environment.

It is clear that not all field conditions will be "dirty" in the same manner. We are therefore not

314 towards the specific conditions in the field (i.e., surgical setup should maximize asepsis as much as

315 local conditions will allow). Another factor that should be evident is that all fish utilized in a

316 tagging study should be healthy overall. Furthermore, precaution is especially needed to prevent

317 possible spreading of pathogens from one fish to the others if it is expected or observed that there 318 are fish exhibiting symptoms of disease. 
321 The study was supported and hosted by the Danish Centre for Wild Salmon, where manager Søren 322 Larsen and biologist Kim Iversen went through great effort to take care of the experimental fish.

323 Thanks to two anonymous referees for constructive comments, that led to significant improvement 324 of the text and Table 2. The study was funded by the Danish rod-licence Fund, Fiskeplejen.

References

Arnold, G.P., Holford, B.H., 1978. The physical effects of an acoustic tag on the swimming performance of plaice and cod. J. Conseil 38, 189-200.

331 Bauer, C., Unfer, G., Loupal, G., 2005. Potential problems with external trailing antennae: antenna migration and ingrowth of epithelial tissue, a case study from a recaptured Chondrostoma nasus. J. Fish Bio. 67, $885-889$. techniques. U.S. Army Corps of Engineers.

Canadian Council on Animal Care, 2005. Guidelines on the care and use of fish in research, teaching, and testing. http://www.ccac.ca/Documents/Standards/Guidelines/Fish.pdf (visited January 2013).

339 Chisholm, I. M., Hubert, W. A., 1985. Expulsion of dummy transmitters by rainbow trout. Trans. Am. Fish. Soc. $114,766-767$.

Chomyshyn, L, McConnachie, S. H., Cooke, S. J., 2011. Evaluation of water entry into the coelom and different levels of aseptic technique during surgical implantation of electronic tags in freshwater. Rev. Fish Biol. Fisher. 21, 61-70. 
Cooke, S. J., Woodley, C. M., Eppard, M. B., Brown, R. S., Nielsen, J. L., 2011. Advancing the surgical implantation of electronic tags in fish: a gap analysis and research agenda based on a review of trends in intracoelomic tagging effect studies. Rev. Fish Biol. Fisher. 21, 127-151.

Daniel, A. J., Hicks, B. J., Ling, N., David, B. O., 2009. Acoustic and radio-transmitter retention in common carp in New Zealand. Mar. Fresh. Res. 60, 328-333.

Elliott, D.G., Pascho, R.J., 2001. Evidence that Coded-Wire-Tagging Procedures Can Enhance Transmission of Renibacterium salmoninarum in Chinook salmon. J. Aquat. Anim. Health 13, 181-193.

Greenstreet, S. P. R., Morgan, R. I. G., 1989. The effect of ultrasonic tags on the growth rates of Atlantic salmon, Salmo salar L., parr of varying size just prior to smolting. J. Fish Biol. 35, 301-309.

Hockersmith, E. E., Muir, W. D., Smith, S. G., Sandford, B. P., Perry, R. W., Adams, N. S., Rondorf, D. W., 2003. Comparison of migration rate and survival between radio-tagged and PIT-tagged migrant yearling Chinook salmon in the Snake and Columbia Rivers. N. Am. J. Fish. Manag. 23, 404-413.

Harms, C. A., Lewbart, G. A., 2011. The veterinarian's role in surgical implantation of electronic tags in fish. Rev Fish Biol Fisher. 21, 25-33.

Jepsen, N., Aarestrup, K., Økland, F., Rasmussen, G., 1998. Survival of radiotagged Atlantic salmon (Salmo salar L.) and trout (Salmo trutta L.) smolts passing a reservoir during seaward migration. Hydrobiologia 371/372, 347-353.

Jepsen, N., Aarestrup, K., 1999. A comparison of the growth of radio-tagged and dye-marked pike. J. Fish Biol. 55, 880-883.

Jepsen, N., Pedersen, S., Thorstad, E.B., 2000. Behavioural interactions between prey (trout smolts) and predators (pike and pikeperch) in an impounded river. Regul. River. 16, 189-198.

Jepsen, N., Davis, L.E., Schreck, C.B., Siddens, B., 2001. The physiological response of chinook salmon smolts to two methods of radio-tagging. Trans. Am. Fish. Soc. 130, 495-500.

Jepsen, N., Mikkelsen, J. S., Koed, A., 2008. Effects of tag and suture type on survival and growth of brown trout with surgically implanted telemetry tags in the wild. J. Fish Biol. 72, 594-602.

Koed, A., Thorstad, E. B., 2001. Long-term effect of radio tagging on the swimming performance of pikeperch. J. Fish Biol. 58, 1753-1756. 
Liedtke, T.L., Beeman, J.W., Gee, L.P., 2012. A standard operating procedure for the surgical implantation of transmitters in juvenile salmonids. USGS Open-File Report, 2012-1267.

Marty, G. D., Summerfelt, R. C., 1986. Pathways and mechanisms for expulsion of surgically implanted dummy transmitters from channel catfish. Trans. Am. Fish. Soc. 115, 577-589.

McCleave, J. D., Stred, K. A., 1975. Effect of dummy telemetry transmitters on stamina of Atlantic salmon (Salmo salar) smolts. J. Fish. Res. Board Can. 32, 559-563.

Wargo-Rub, A. M., Sandford, B. P., Gilbreath, L. G., Myers, M. S., Peterson, M. E., Charlton, L. L., Smith,

Wagner, G. N., Stevens, E. D., Byrne, P., 2000. Effects of suture type and patterns on surgical wound healing in rainbow trout. Trans. Am. Fish. Soc. 129, 1196-1205.

Wagner, G.N., Cooke, S.J., 2005. Methodological approaches and opinions of researchers involved in the surgical implantation of telemetry transmitters in fish. J. Aquat. Anim. Health 17, 160-169.

S. G., Matthews, G. M., 2011. Comparative performance of acoustic tagged and passive integrated transponder tagged juvenile Chinook Salmon in the Columbia and Snake Rivers, 2008. Report of the 
398 National Marine Fisheries Service to the U.S. Army Corps of Engineers, Portland District, Portland, 399 Oregon. (http://www.nwfsc.noaa.gov/assets/26/7950_01252012_152630_PIT-AT-Tag-Comparison$400 \quad$ 2008.pdf)

401

402

403 
1 Table 1. Key information about the experimental fish. Specific growth rates are medians, calculated by the formula $\mathrm{G}_{\mathrm{L}}=\left(\ln \mathrm{L}_{2}-\ln \mathrm{L}_{1}\right)^{*} t^{-1}$ (see text). Clean refer to fish tagged under aseptic conditions and dirty to fish tagged under non-aseptic conditions. A = tags with trailing antenna and $\mathrm{NA}=$ tags without antenna.

5

\begin{tabular}{ccccc}
\hline Treatment & N-tagged & Mortalities & $\begin{array}{c}\text { Specific } \\
\text { length growth } \\
\text { (Var) }\end{array}$ & $\begin{array}{c}\text { Healing } \\
\text { (Median) }\end{array}$ \\
\hline Clean-A & 25 & 3 & $0.04(0.0155)$ & 1.88 \\
Dirty-A & 25 & 4 & $0.06(0.0054)$ & 1.76 \\
Clean-NA & 25 & 1 & $0.09(0.0065)$ & 1.79 \\
Dirty-NA & 25 & 2 & $0.07(0.0139)$ & 1.71 \\
\hline
\end{tabular}


Table 2. Summarized findings from post-mortem examinations of fish 5 and 34 days after tagging under aseptic (clean) or non-aseptic (dirty) conditions.

\begin{tabular}{|c|c|c|c|c|c|c|c|c|}
\hline \multirow[b]{3}{*}{ Category } & \multicolumn{4}{|c|}{5 Days Post Surgery } & \multicolumn{4}{|c|}{34 Days Post Surgery } \\
\hline & \multicolumn{2}{|c|}{$\begin{array}{l}\text { Clean, } \\
\mathrm{N}=4\end{array}$} & \multicolumn{2}{|c|}{ Dirty, $N=4$} & \multicolumn{2}{|c|}{$\begin{array}{l}\text { Clean, } \\
\mathrm{N}=20\end{array}$} & \multicolumn{2}{|c|}{ Dirty, $N=19$} \\
\hline & Yes & No & Yes & No & Yes & No & Yes & No \\
\hline \multicolumn{9}{|l|}{ Antenna Present } \\
\hline Adhesion & 4 & 0 & 2 & 2 & 15 & 3 & 16 & 1 \\
\hline Tag Free in Cavity & 0 & 0 & 0 & 0 & 8 & 10 & 10 & 7 \\
\hline Inflammation/Hemorrhages & 4 & 0 & 4 & 0 & 3 & 15 & 3 & 14 \\
\hline In Pocket & 4 & 0 & 2 & 2 & 10 & 8 & 5 & 12 \\
\hline Encapsulated & 0 & 0 & 0 & 0 & 3 & 15 & 4 & 13 \\
\hline \multirow[t]{2}{*}{ Expulsion Progressing } & 0 & 0 & 0 & 0 & 2 & 16 & 2 & 15 \\
\hline & \multicolumn{2}{|c|}{$\begin{array}{c}\text { Clean, } \\
\mathrm{N}=4\end{array}$} & \multicolumn{2}{|c|}{ Dirty, $N=4$} & \multicolumn{2}{|c|}{$\begin{array}{l}\text { Clean, } \\
\mathrm{N}=20\end{array}$} & \multicolumn{2}{|c|}{ Dirty, $N=19$} \\
\hline \multicolumn{9}{|l|}{ No Antenna } \\
\hline Adhesion & 4 & 0 & 3 & 1 & 19 & 1 & 16 & 3 \\
\hline Tag Free in Cavity & 0 & 0 & 0 & 0 & 6 & 14 & 6 & 13 \\
\hline Inflammation/Hemorrhages & 4 & 0 & 3 & 1 & 0 & 20 & 3 & 16 \\
\hline In Pocket & 0 & 4 & 0 & 4 & 11 & 9 & 10 & 9 \\
\hline Encapsulated & 0 & 0 & 0 & 0 & 9 & 11 & 7 & 12 \\
\hline Expulsion Progressing & 0 & 0 & 0 & 0 & 4 & 16 & 4 & 15 \\
\hline
\end{tabular}



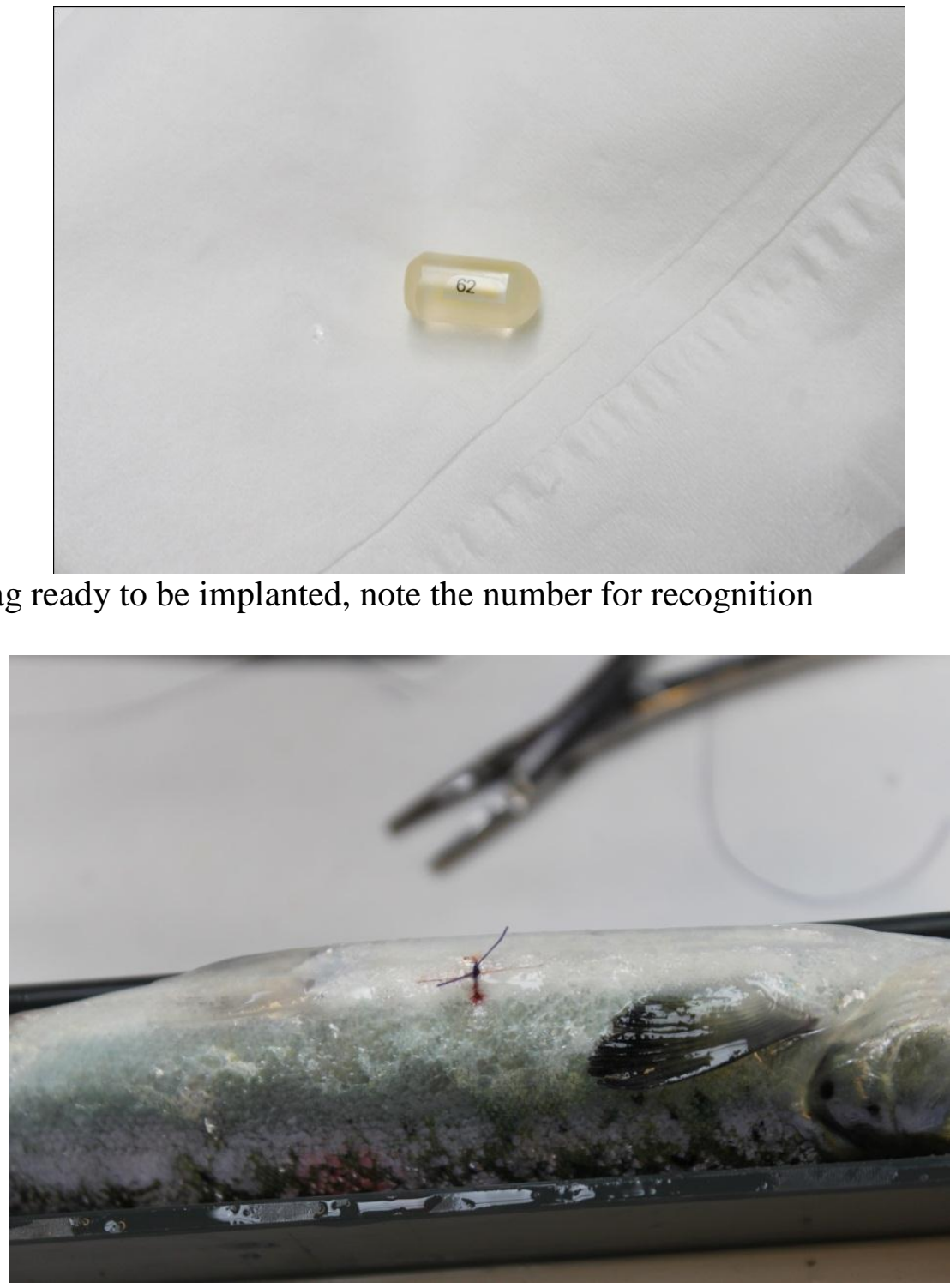

6 A freshly tagged smolt, ready for recovery 7

8

9

10 


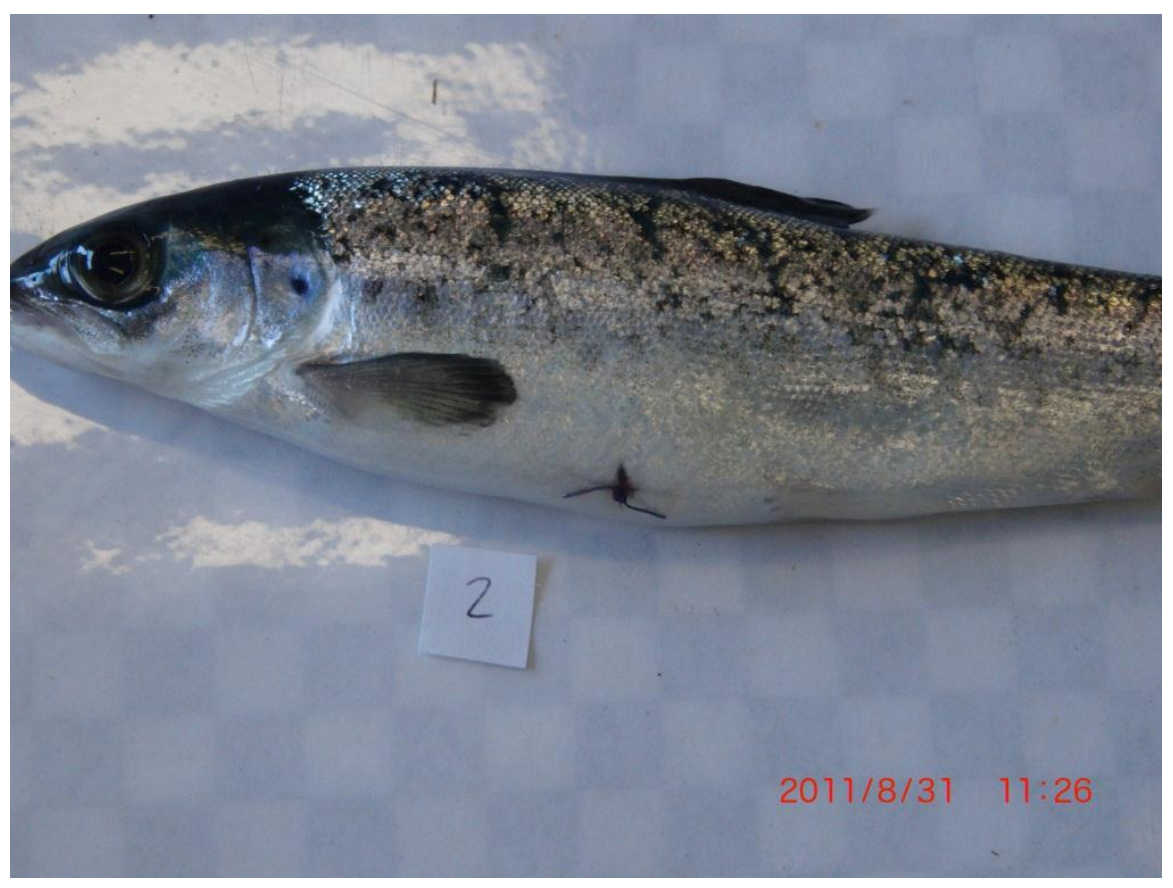

34 days post surgery, note the suture material is still in place

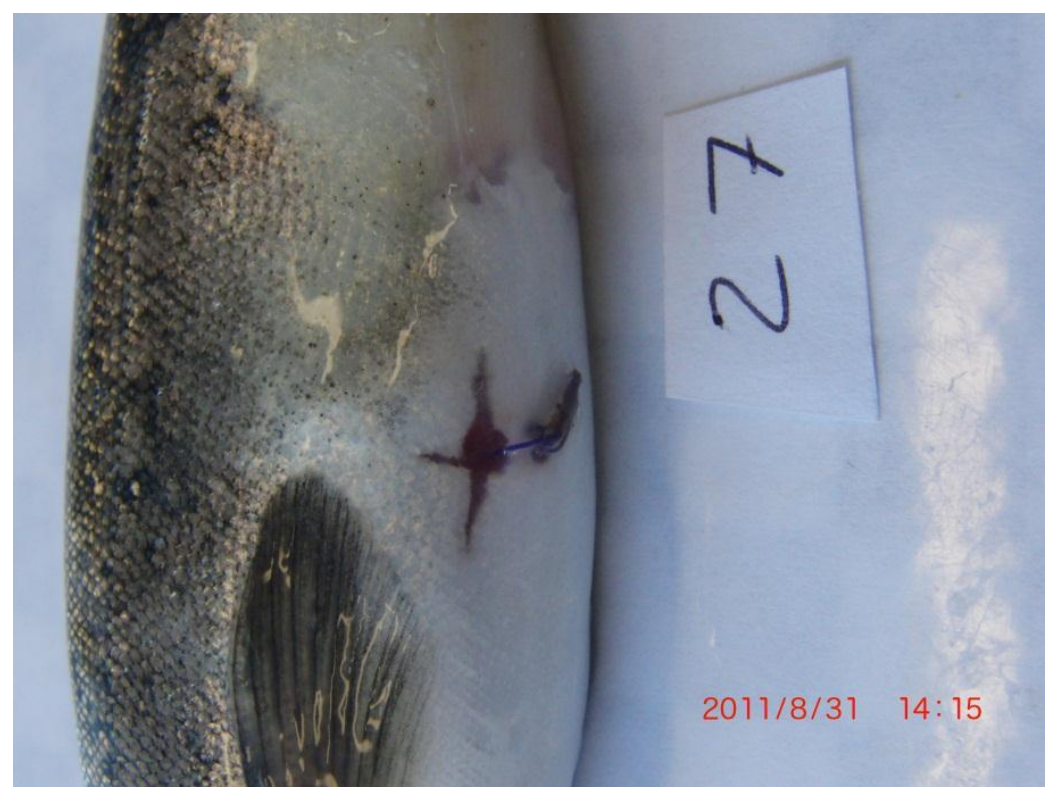

534 days post surgery, note how the suture has been causing irritation and necrosis 


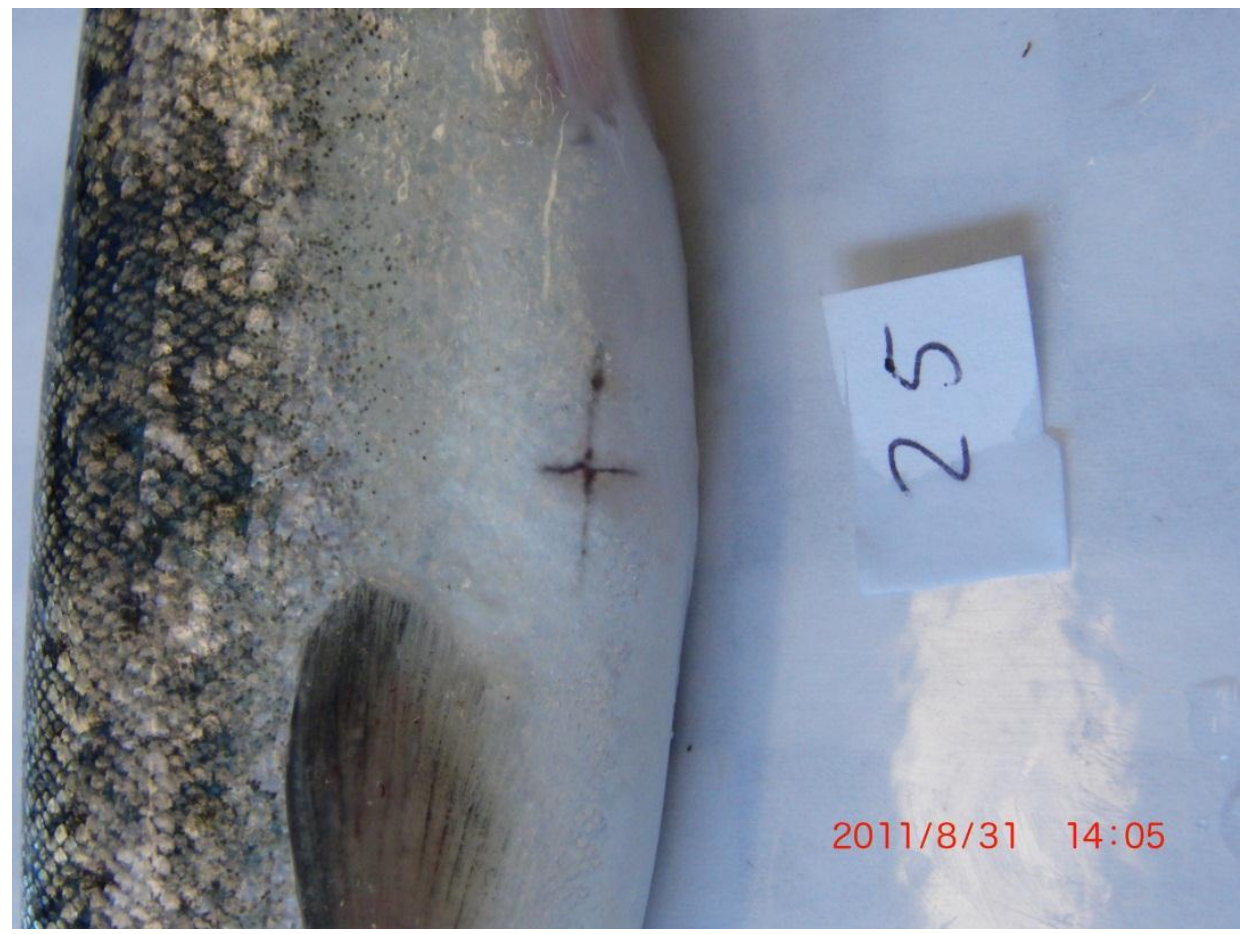

234 days post surgery, this fish has shed the suture, but it is evident that the skin was ruptured during 3 the process. This is very often seen, despite the use of thin absorbable suture.

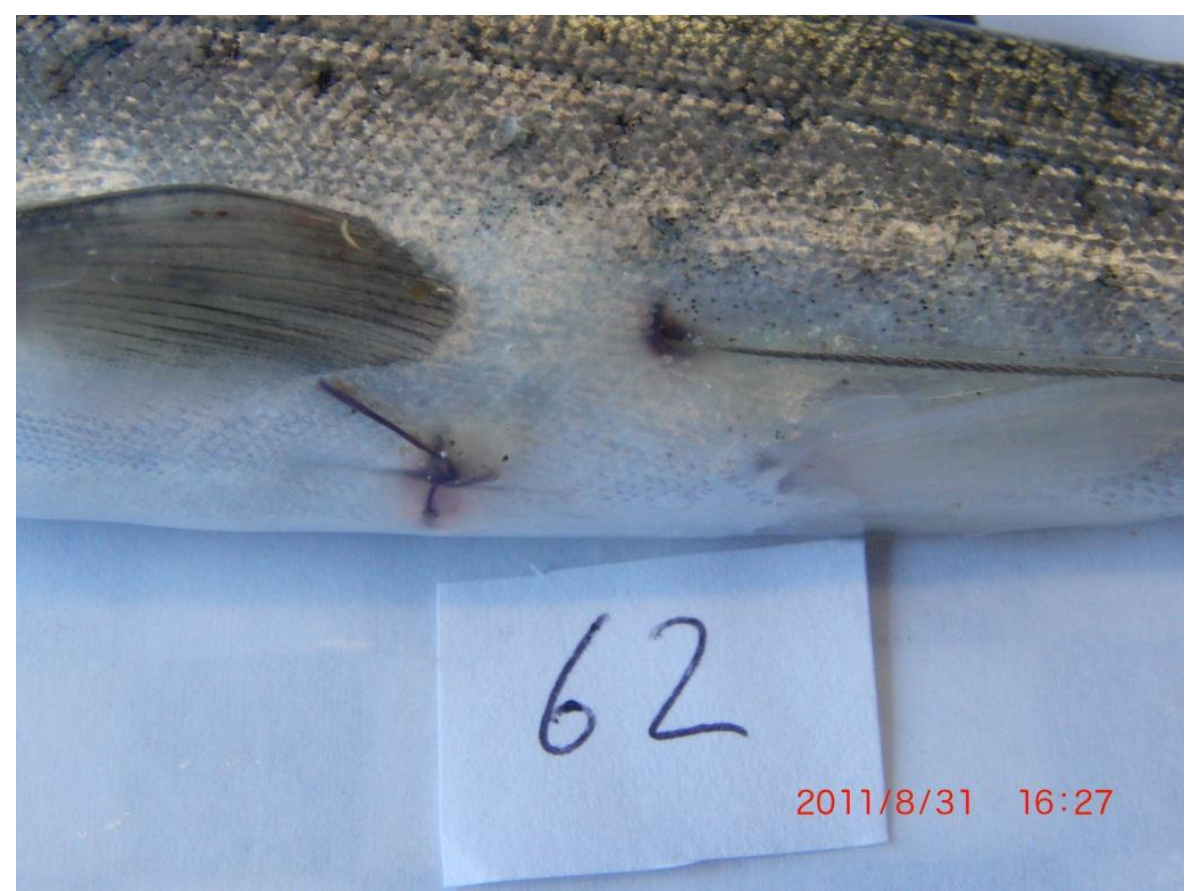

34 days post surgery, this is a fish with trailing antenna, note again the suture causing irritation, 7 whereas the incision is almost healed. 


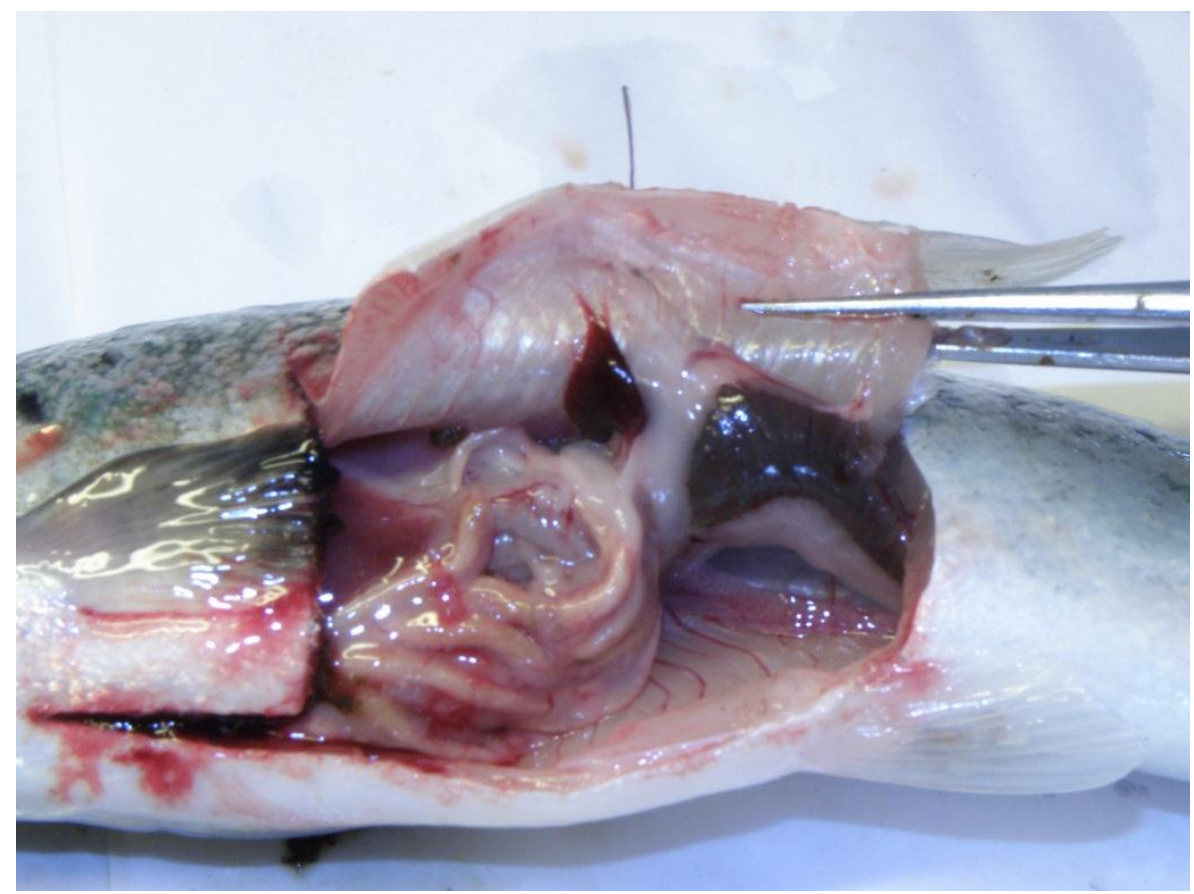

34 days post surgery, here we see adhesion, involving the spleen.

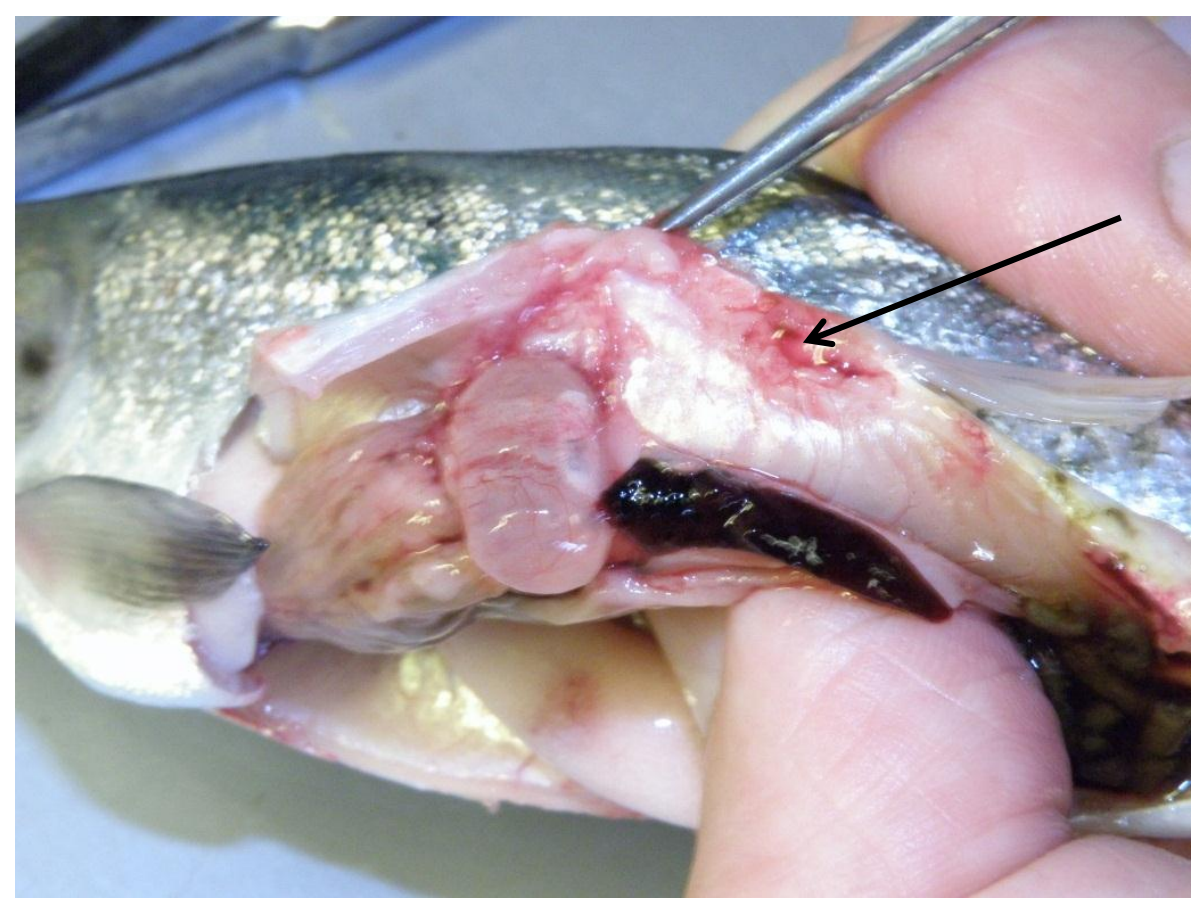

34 days post surgery, a NA-dummy has been fully encapsulated and expulsion was in progress, arrow indicating the grove where the muscles were degraded to facilitate expulsion through the side. 


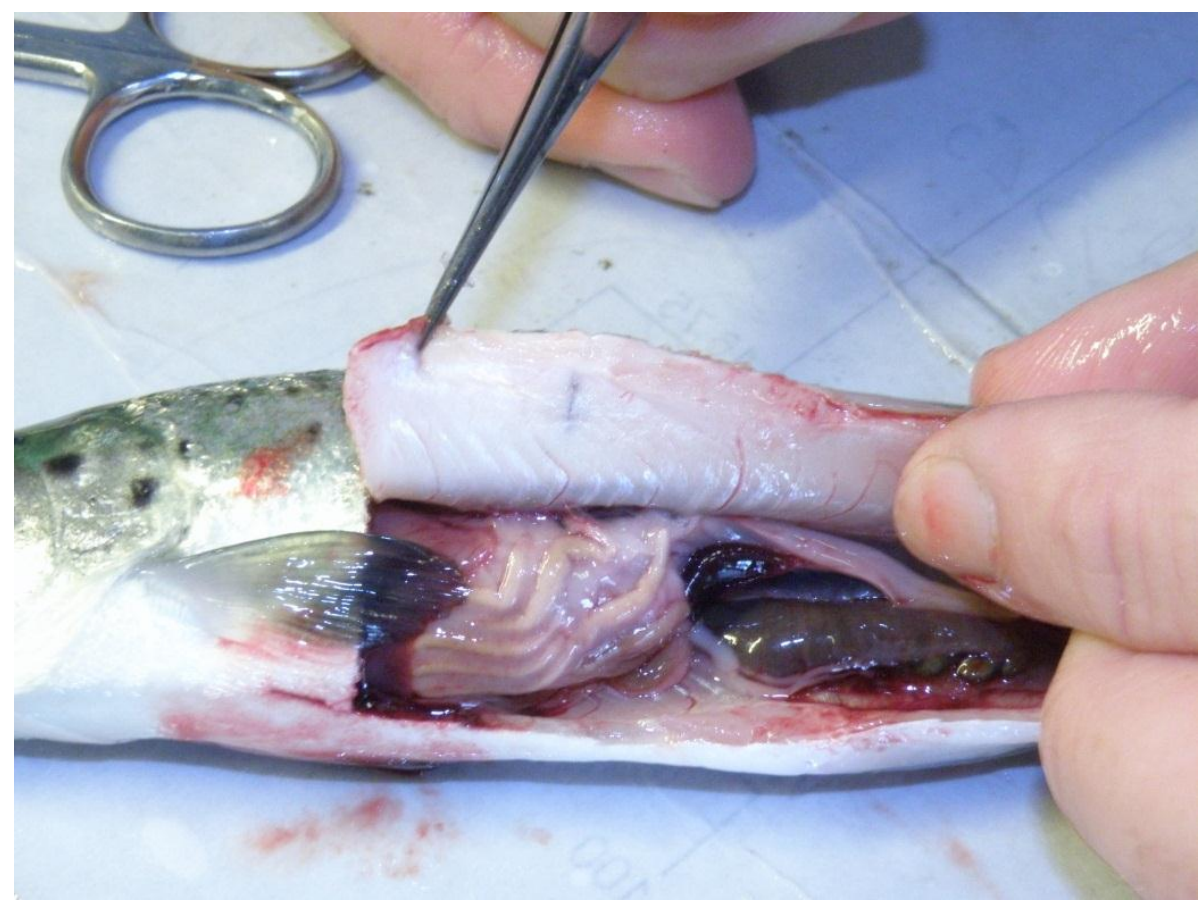

134 days post surgery, a well healed fish, without adhesion. 